Article

\title{
An Investigation of the High-Frequency Ultrasonic Vibration-Assisted Cutting of Steel Optical Moulds
}

\author{
Canbin Zhang ${ }^{1, *(\mathbb{D}}$, Chifai Cheung ${ }^{1} \mathbb{D}$, Benjamin Bulla ${ }^{2}$ and Chenyang Zhao ${ }^{1,3} \mathbb{C}$ \\ 1 State Key Laboratory of Ultra-Precision Machining Technology, Department of Industrial and Systems \\ Engineering, The Hong Kong Polytechnic University, Hung Hom, Kowloon, Hong Kong, China; \\ benny.cheung@polyu.edu.hk (C.C.); zhaochenyang@hit.edu.cn (C.Z.) \\ 2 Son-x Gmbh, 52078 Aachen, Germany; benjamin.bulla@son-x.com \\ 3 School of Mechanical Engineering and Automation, Harbin Institute of Technology, Shenzhen 518055, China \\ * Correspondence: canbin.zhang@connect.polyu.hk; Tel.: +852-5623-2030
}

Citation: Canbin, Z.; Chifai, C.;

Benjamin, B.; Chenyang, C.

An Investigation of the High-

Frequency Ultrasonic Vibration-

Assisted Cutting of Steel Optical

Moulds. Micromachines 2021, 12, 460.

https://doi.org/10.3390/mi12040460

Academic Editor: Xichun Luo

Received: 31 March 2021

Accepted: 16 April 2021

Published: 19 April 2021

Publisher's Note: MDPI stays neutral with regard to jurisdictional claims in published maps and institutional affiliations.

Copyright: (c) 2021 by the authors. Licensee MDPI, Basel, Switzerland. This article is an open access article distributed under the terms and conditions of the Creative Commons Attribution (CC BY) license (https:/ / creativecommons.org/licenses/by/ $4.0 /)$.

\begin{abstract}
Ultrasonic vibration-assisted cutting (UVAC) has been regarded as a promising technology to machine difficult-to-machine materials such as tungsten carbide, optical glass, and hardened steel in order to achieve superfinished surfaces. To increase vibration stability to achieve optical surface quality of a workpiece, a high-frequency ultrasonic vibration-assisted cutting system with a vibration frequency of about $104 \mathrm{kHz}$ is used to machine spherical optical steel moulds. A series of experiments are conducted to investigate the effect of machining parameters on the surface roughness of the workpiece including nominal cutting speed, feed rate, tool nose radius, vibration amplitude, and cutting geometry. This research takes into account the effects of the constantly changing contact point on the tool edge with the workpiece induced by the cutting geometry when machining a spherical steel mould. The surface morphology and surface roughness at different regions on the machined mould, with slope degrees (SDs) of $0^{\circ}, 5^{\circ}, 10^{\circ}$, and $15^{\circ}$, were measured and analysed. The experimental results show that the arithmetic roughness $S_{a}$ of the workpiece increases gradually with increasing slope degree. By using optimised cutting parameters, a constant surface roughness $S_{a}$ of $3 \mathrm{~nm}$ to $4 \mathrm{~nm}$ at different slope degrees was achieved by the applied high-frequency UVAC technique. This study provides guidance for ultra-precision machining of steel moulds with great variation in slope degree in the pursuit of optical quality on the whole surface.
\end{abstract}

Keywords: high frequency; ultrasonic-assisted vibration cutting; difficult-to-machine material; spherical steel mould; ultra-precision machining

\section{Introduction}

Steel is a fascinating die material in the precision mould industry for injection moulding of plastic optical lenses and low-Tg glass. To machine steel materials, coated carbide tools [1,2] and cubic boron nitride (CBN) tools [3] are widely applied. Diamond tools possess a nanometric edge radius, form reproducibility, and excellent wear resistance, so they are extensively used in ultra-precision machining technology, such as fly cutting and single-point diamond turning (SPDT), and are capable of producing components with submicrometric form accuracy and surface roughness in the nanometre range on plastic and non-ferrous materials such as copper, aluminium, brass, etc. [4]. However, diamond machining of ferrous materials such as steel is not amenable due to excessive tool wear caused by the chemical affinity of carbon to iron [5]. Guo et al. [6] conducted a critical review of the chemical wear and wear-suppressing methods of diamond tools in the diamond cutting of ferrous materials. To reduce the chemical reaction and wear on the diamond tool and to hence improve the surface quality of the workpiece, researchers have been putting great efforts into the development of a variety of strategies. These strategies include creating a cryogenic [7] or carbon-saturated inert gas atmosphere [8], applying 
vibration-assisted machining [9], depositing a protective coating on the cutting tool [10], and using a ceramic tool [11].

Taking into consideration ease and economical machine setup as well as great machining stability and reliability, vibration-assisted machining has been considered a promising technique with widespread use in the industry. Vibration-assisted machining enables superior cutting performance, such as smaller cutting forces, better surface finishing, higher cutting stability, and longer tool life [12,13]. Moriwaki and Shamoto [9] first used ultrasonic vibration-assisted cutting (UVAC, Conventional Ultrasonic Vibration Cutting, CUAC, or 1D UVC) for ultra-precision diamond turning of stainless steel. A mirror-like quality with surface roughness of $26 \mathrm{~nm}$ was achieved, and this demonstrated the technical feasibility of ultra-precision diamond machining of steel. Subsequently, the technique of ultrasonic elliptical vibration cutting (UEVC) was firstly proposed by Shamoto and Moriwaki [12] and was used to machine hardened steel [13]. The experimental results showed that smaller cutting forces and longer tool life were achieved by the UEVC method in comparison to those in both conventional cutting and CUVC.

The optical surface quality for which the required surface roughness can be roughly determined as less than $10 \mathrm{~nm}$ according to various optical functions [14,15] is vital for ensuring the functional performance of the workpiece for optical application. Zhang et al. [16] conducted face-turning experiments on hardened steel by using the UEVC method with poly-crystalline diamond (PCD) tools under various nominal cutting speeds, depths of cut, and feed rates. Mirror-like surfaces were obtained, and the surface roughness of $10 \mathrm{~nm}$ was achieved under an optimal combination of cutting parameters. However, a constant surface roughness of less than $10 \mathrm{~nm}$ is still challenging in UVAC or UEVC of steel with a common vibration frequency of less than $40 \mathrm{kHz}$.

To study the influence of vibration frequency on surface roughness, Klocke et al. [17] conducted ultrasonic vibration-assisted turning under various parameters on steel with hardnesses of both $35 \mathrm{HRC}$ and $50 \mathrm{HRC}$ at vibration frequencies of both $40 \mathrm{kHz}$ and $60 \mathrm{kHz}$. By comparing the obtained surface roughness, they found that the surface roughness at a vibration frequency of $60 \mathrm{kHz}$ was more stable and smaller (most are below $10 \mathrm{~nm}$ ). This may be due to the fact that a smaller amplitude is required for the same contact ratio between the tool and workpiece during the cutting process by increasing the vibration frequency from $40 \mathrm{kHz}$ to $60 \mathrm{kHz}$, leading to a stable cutting process and thus higher surface quality. More importantly, the stable cutting process is due to the smaller cutting force resulting from a smaller upfeed stroke in each vibration cutting cycle by increasing the vibration frequency.

Based on this, ultrasonic tooling systems with operating frequencies of $80 \mathrm{kHz}$ [18] and $104 \mathrm{kHz}$ [19] were developed by the German company Son-x GmbH and have been used in diamond turning of spherical and aspherical surfaces on steel with sub-micrometre form accuracy and nanometric surface roughness. Unlike the conventional ultrasonic tooling system in which the sonotrode vibrates in the longitudinal mode or the first-order bending mode, the sonotrode in the $104 \mathrm{kHz}$ vibration system works in a multi-order bending mode. This mode produces a primary transversal vibration in the cutting direction as well as a secondary longitudinal vibration in the thrust direction, both of which are fused into a new vibration trajectory [19].

Although sub-micrometre form accuracy and nanometric surface roughness can be achieved with the newly developed $104 \mathrm{kHz}$ ultrasonic tooling system, there are few studies that systematically investigate the effect of cutting parameters on surface roughness with this vibration setup so the setup's machining stability and reliability need to be further examined. Moreover, little research on the surface finish in ultrasonic vibration-assisted cutting of steel considers the effects of the machining geometry of the workpiece. Therefore, this study aimed to investigate the effect of cutting parameters such as nominal cutting speed, feed rate, tool nose radius, and vibration amplitude on the surface roughness of the workpiece by making use of the Taguchi orthogonal experiment. In addition, the surface roughness of spherical moulds with various slope degrees were measured and analysed to 
explore the effect of the machined geometry on surface quality in the ultrasonic vibrationassisted cutting of spherical optical steel moulds.

\section{Working Principle and Cutting Mechanics Of UVAC}

\subsection{Cutting Mechanics}

In ultrasonic vibration-assisted cutting, the cutting tool is equipped with vibration moving up and down at an ultrasonic frequency, parallel to the cutting direction. The vibration displacement and the vibration speed can be determined by Equations (1) and (2), respectively [20]:

$$
\begin{gathered}
x=A \sin (2 \pi f t) \\
x^{\prime}=2 \pi f A \cos (2 \pi f t)
\end{gathered}
$$

where $A$ and $f$ are the vibration amplitude and vibration frequency, respectively. If the maximal speed of vibration $(2 \pi f A)$ is larger than the nominal cutting speed $v_{c}$, the separation between the rake face of the cutting tool and the cutting zone of the workpiece occurs. This separation is a characteristic of ultrasonic vibration-assisted cutting that can enhance lubrication and cooling conditions and thus reduce the cutting forces and tool wear, thereby improving the cutting stability and the surface finish $[12,13]$.

To better understand the cutting process of UVAC, Figure 1a is a schematic diagram of the relative position between the tool tip and the workpiece in the UVAC process. Several important time moments at $t 1, t 2, t 3, t 4$, and $t 1^{\prime}$ in one cutting cycle are discussed and their corresponding dynamics are shown in Figure $1 \mathrm{~b}$. The three curves represent the vibration displacement, vibration speed, and nominal cutting speed relative to the static coordinate system. At the moments of $t 1$ and $t 2$, the vibration speed and the nominal cutting speed are equal. $t 1$ and $t 2$ can be determined by solving Equation (3) as follows [20]:

$$
2 \pi f A \cos (2 \pi f t)=-v_{c}
$$

(a)

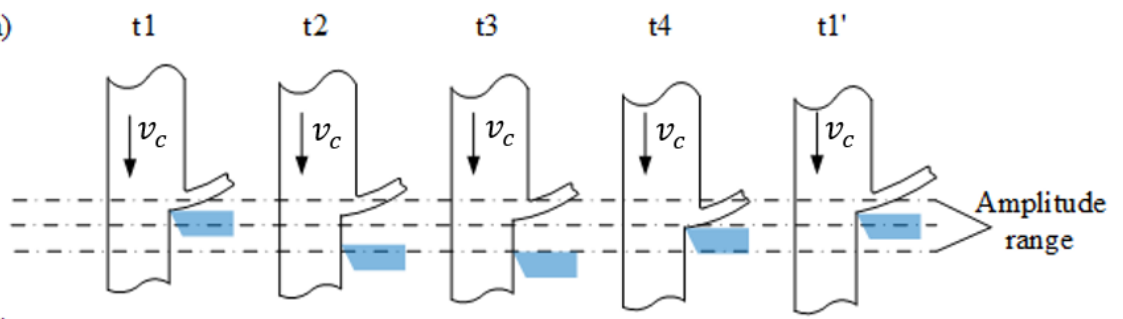

(b)

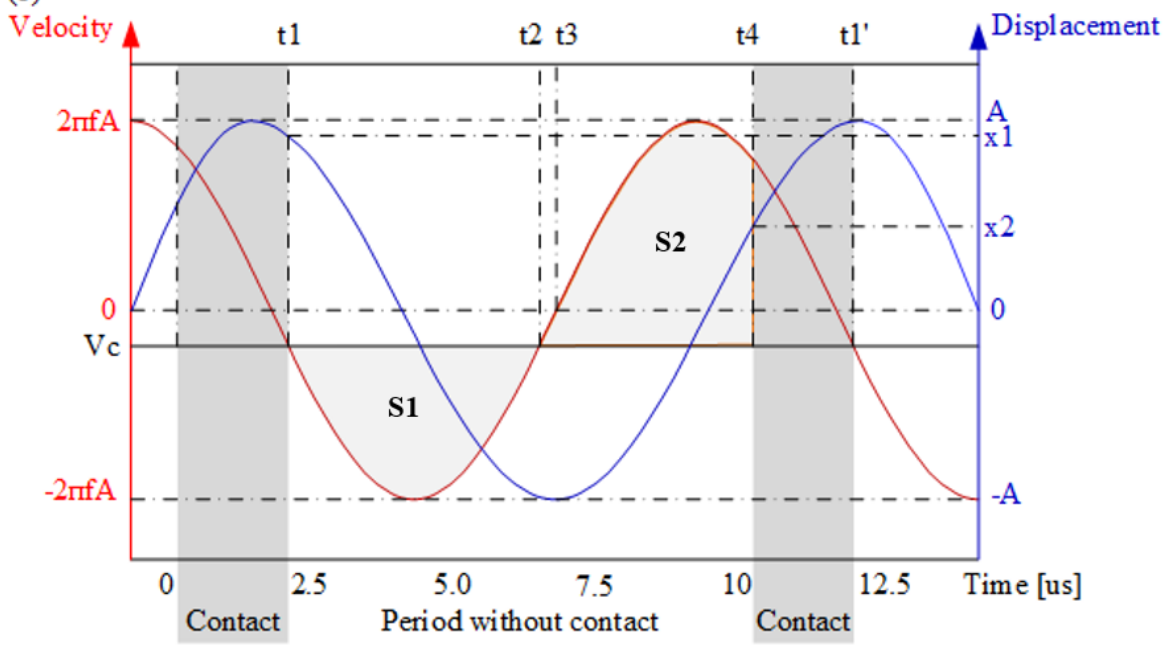

Figure 1. (a) Schematic diagram of the position relationship between the tool and the workpiece in UVAC. (b) The kinematics of UVAC. 
At $t 1$, the cutting tool starts to separate from the cutting zone of the workpiece, and the corresponding vibration displacement is $x_{2}=A \sin (2 \pi f t 1)$. At $t 2$, the distance between the tool and the workpiece reaches the maximum value, which is the area of S1, as shown in Figure $1 b$. After $t 2$, the distance between the tool and the workprice starts to decrease. At $t 3$, the vibration motion reaches the lowest point, and then starts to move upward. The area of S2 as shown in Figure 1b shows a decreasing distance between the tool and the cutting zone of the workpiece after $t 2$. When the areas of these two parts are equal $(\mathrm{S} 1=\mathrm{S} 2)$, at $t 4$, the tool contacts the cutting zone of the workpiece again for cutting until $t 1^{\prime}$, and then one cutting cycle $\mathrm{T}$ is completed. After this, the tool and the cutting zone of the workpiece separate again and enter the next cutting cycle. The vibration position at $t 4$ is $x_{2}=A \sin (2 \pi f t 4)$.

From $t 1$ to $t 4$, the displacement of vibration is $\Delta x$ :

$$
\Delta x=x_{1}-x_{2}=A \sin ((2 \pi f t 1)-A \sin (2 \pi f t 4)
$$

The displacement of the workpiece is $s=v_{\mathcal{c}}(t 4-t 1)$. The condition for the tool contacting the cutting zone of the workpiece again is $\Delta x=s$ :

$$
\Delta x=s \rightarrow A \sin (2 \pi f t 1)-A \sin (2 \pi f t 4)=v_{\mathcal{c}}(t 4-t 1)
$$

The time point $t 4$ can be solved numerically. To be specific, it can be solved by gradually increasing the number of time units $d t$, namely $n$, starting from $t 1$. When $A \sin (2 \pi f t 1)-A \sin (2 \pi f(t 1+n d t))=v_{c} n d t$ is satisfied within the error tolerance, it is assumed that $n=N$. Therefore, $t 4=t 1+N d t$.

The contact ratio of the tool tip with the cutting zone of the workpiece, namely 'Duty Cycle $(D C)^{\prime}$, is expressed as follows [20]:

$$
D C=\frac{T-(t 4-t 1)}{T}=(T-N d t) f
$$

Given that the vibration frequency $f$ is constant, the speed ratio of nominal cutting speed $v_{\mathcal{C}}$ to the maximal vibration speed $2 \pi f A$ can be varied by changing the value of $v_{\mathcal{C}}$ or $A$. When the speed ratio is ascertained, the corresponding duty cycle can be determined by solving Equations (3)-(6). In this way, the duty cycle for various speed ratios can be calculated. Figure 2 shows the duty cycle as a function of the speed ratio of the nominal cutting speed to the maximal vibration speed. The duty cycle decreases with decreasing speed ratio. It is believed that a smaller DC means better lubrication and cooling, which leads to a smaller cutting force and better surface quality [21]. In UVAC, under constant nominal cutting speed $v_{c}$, a higher vibration frequency leads to a smaller speed ratio and thus a smaller $D C$ at a constant vibration amplitude or a smaller vibration amplitude at a constant $D C$. Both result in stabilised vibration and better surface quality.

\subsection{The Applied High-Frequency UVAC}

The vibration equipment Son-X UTS2 was used in this research. This ultrasonic tooling system was designed and described in the previous literature [19]. The transducer and sonotrode are actuated at the resonant frequency of $104 \mathrm{kHz}$, and the sonotrode works in the multi-order bending mode. During the cutting stage, the tool tip has both transversal vibration (blue line) and longitudinal vibration (red line), with a phase difference of $180^{\circ}$, as shown in Figure 3a. The amplitude ratio of the transversal and longitudinal vibration is about 5:1 (i.e., the longitudinal vibration amplitude is $200 \mathrm{~nm}$ when the transversal vibration amplitude is $1 \mu \mathrm{m}$ ). The differences in phase and amplitude between transversal and longitudinal vibration are finally fused into a slight-incline vibration track relative to the transversal direction, namely the cutting direction, and this vibration leads to a sawlike trajectory of the tool tip relative to the workpiece under a nominal cutting speed $v_{\mathcal{C}}$, as shown in Figure 3b. Compared with UVAC, it is interesting to note that the tool tip includes an additional component motion in the thrust direction. This enables the tool 
tip to completely separate from the finished surface when the tool is withdrawn from the workpiece. This characteristic can facilitate contact between the coolant and lubricant, and the flank face of the cutting tool, or contact between oxygen in the air and the freshly cutting surface when cutting ferrous materials $[22,23]$, thereby reducing the tool wear rate.

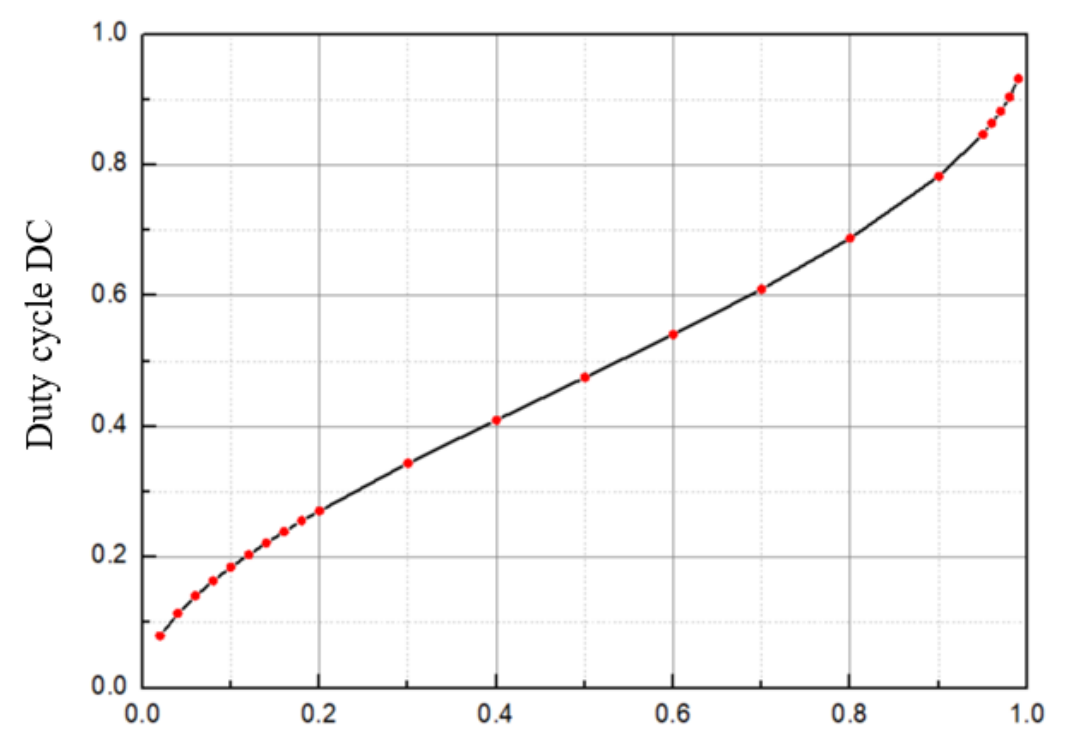

Ratio of the nominal cutting speed to the maximal vibration speed

Figure 2. Relationship between the duty cycle and the speed ratio.

(a)

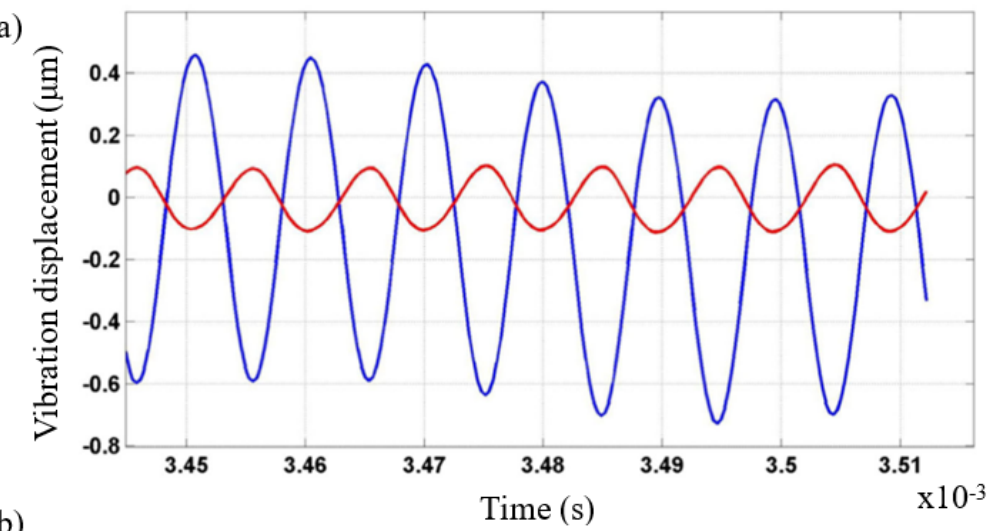

(b)
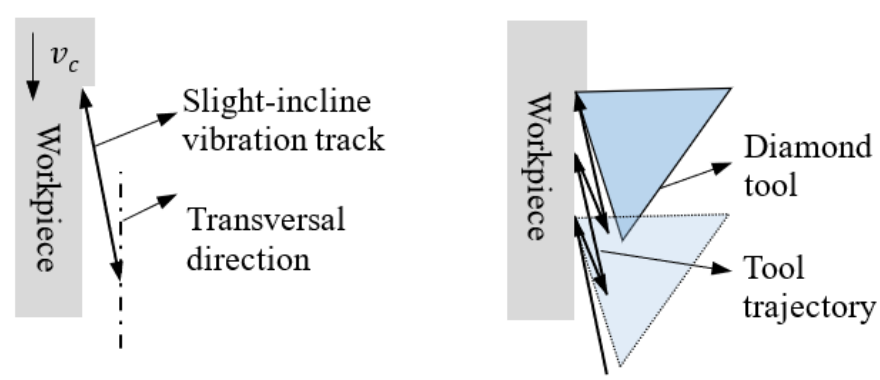

Figure 3. (a) Diamond tool tip transversal vibration displacement (blue line) and longitudinal vibration displacement (red line) during the cutting stage [19]. (b) Schematic of the tool tip movement of the slight-incline UVAC.

\section{Experiment}

\subsection{Machining Dimension and Material of the Moulds}

Figure $4 \mathrm{a}, \mathrm{b}$ show diagrams of a concave and convex spherical mould, respectively. Both have a spherical surface with a radius of $15 \mathrm{~mm}$. The concave mould has an aperture 
of $12 \mathrm{~mm}$ and a maximum slope degree of $23.6^{\circ}$. The convex mould has an aperture of 15 $\mathrm{mm}$ and a maximum slope degree of $30^{\circ}$.

(a)

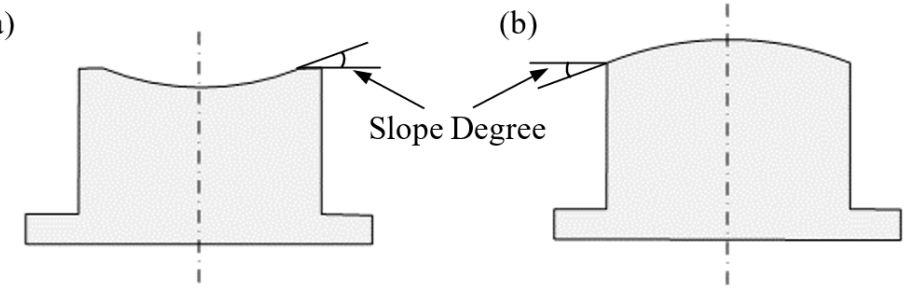

Figure 4. Diagram of the spherical moulds: (a) concave and (b) convex.

The geometry of the spherical surface could have an effect on the cutting force components as well as the surface roughness of the machined workpiece since it leads to variation in the cutting position of the tool edge. Taking the cutting process of the concave mould as shown in Figure 5, during the cutting process, the cutting edge of the diamond tool moves inwards to the center of the workpiece along the spherical surface. In this process, the point on the workpiece in contact with the cutting tool transfers from E to D, C, and B, and then to $\mathrm{A}$, which has a slope degree of $20^{\circ}, 15^{\circ}, 10^{\circ}, 5^{\circ}$, and $0^{\circ}$, respectively. This process also results in variation in the cutting point on the tool and their cutting angles $\theta$, namely the angle between the symmetric line of the tool rake face and the normal line of the tool edge at these points, which are correspondingly $20^{\circ}, 15^{\circ}, 10^{\circ}, 5^{\circ}$, and $0^{\circ}$. The variation in the cutting position and the cutting angle could possibly induce a difference in the cutting force and surface quality, which is worth studying.

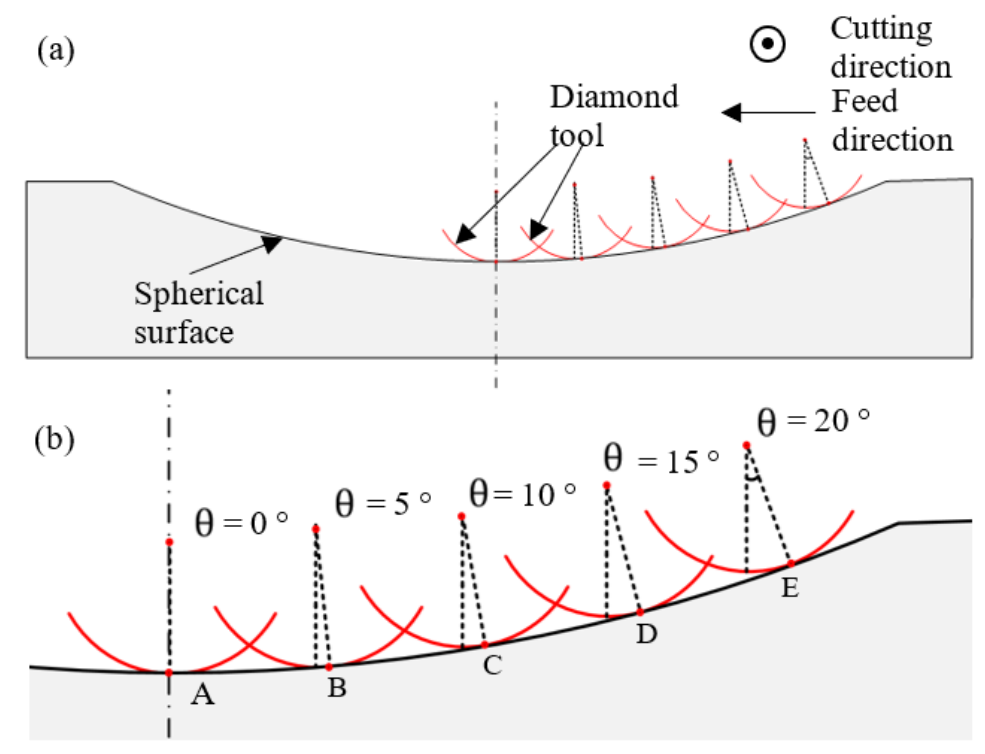

Figure 5. (a) Schematic diagram of cutting a concave spherical mould. (b) A partial enlarged view of (a).

The material used in this study was Mirrax 40 steel. Mirrax 40 is a remelted stainless steel prehardened to $40 \mathrm{HRC}$. It has excellent machinability, polishability, ductility, and toughness, which make it appropriate for injection moulds, extrusion dies, and flow moulds. The chemical composition of Mirrax 40 steel includes (wt.\%): C: 0.21, Si: 0.9, Mn: 0.45, Cr: 13.5, Mo: 0.2, Ni: 0.6, and V: 0.25 .

\subsection{Procedures and Setup}

The spherical surface turning experiments were conducted on an ultra-precision machine (Nanotech 450 from Nanotechnology Inc., Los Angeles, CA, USA) equipped with 
an ultrasonic vibration-assisted diamond machining system (i.e., Son-X UTS2 from Son- $X$ $\mathrm{GmbH}$ Germany), which was installed on the Z-axis guide, as shown in Figure 6. In each experiment, the constant surface speed (CSS) mode was utilised. The spindle rotational speed increased steadily to keep the nominal cutting speed constant at different areas on the spherical surface with various diameters when the cutting tool moved inwards. Since the spindle rotational speed could not increase infinitely with the cutting tool moving close to the centre of the workpiece, it was kept constant until the cut was finished after the spindle speed reached $300 \mathrm{rpm}$. A rough cut of $10 \mu \mathrm{m}$ per rev, $5 \mu \mathrm{m}$ depth-of-cut, and $4 \mathrm{~m} / \mathrm{min}$ cutting speed were firstly conducted to eliminate the dimensional error of the workpiece, followed by a finishing cut under specific parameters. After the finishing cut, the surface quality of the machined mould was evaluated and the surface roughness was measured using the New Zygo NexView Optical Profiler (USA). To directly and accurately measure the surface roughness of the areas at different slope degrees on the mould surface, an angle inclinometer was used for rotation of the workpiece. The arithmetic roughness $S_{a}$ of the areas with the slope degrees of $0^{\circ}, 5^{\circ}, 10^{\circ}$, and $15^{\circ}$ were measured and analysed.

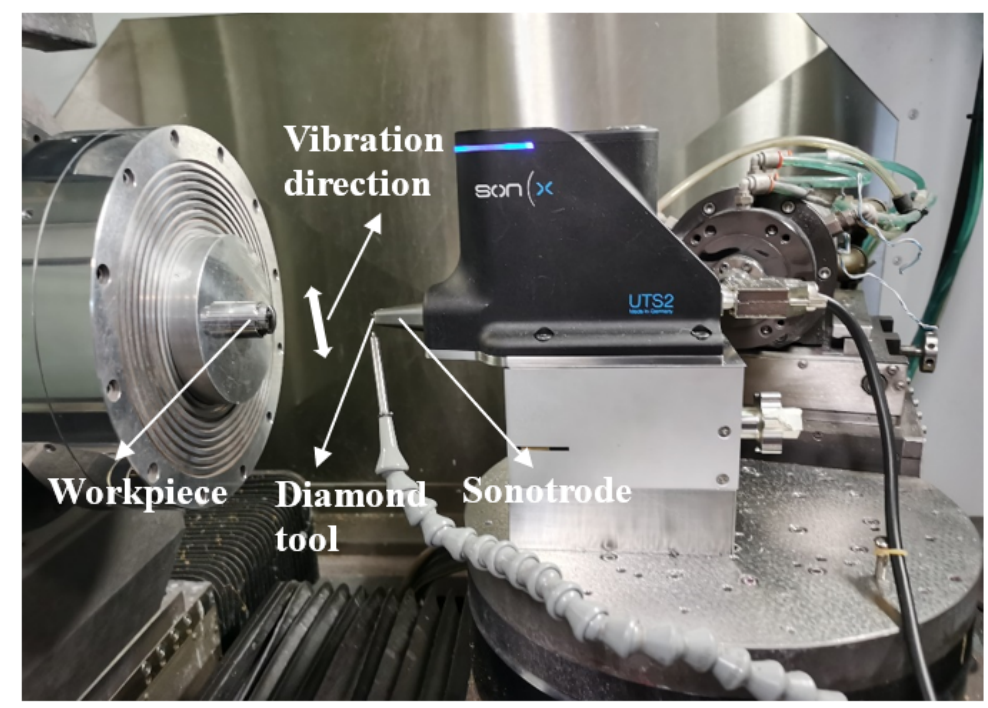

Figure 6. Photo of the machining setup.

\subsection{Experimental Design Using the Taguchi Method}

The Taguchi method [2,3,24] is an engineering approach used to investigate the effects of process parameters on the target performance for optimisation of these parameters. Designing an orthogonal array test can greatly reduce the experimental trials and then quickly identify key parameters. The possible key parameters in ultrasonic vibrationassisted cutting that may have significant effects on surface roughness are the tool radius (TR), cutting speed (CS, namely nominal cutting speed), vibration amplitude, feed rate (FR), and surface form. For the Son-X UTS2, the vibration amplitude of the vibrator is associated with the input current (IC). The larger the input current, the larger the vibration amplitude. As a result, the five parameters including TR, CS, IC, FR, and surface form were identified as five experimental factors for ultrasonic vibration-assisted cutting of the spherical moulds in this study. Based on the previous study, three levels for each factor (except the surface form with two levels of concave and convex) were selected to cover the research interest, as shown in Table 1 . The rake angle and clearance angle of the cutting tool were $0^{\circ}$ and $10^{\circ}$. The peak-to-peak vibration amplitudes were approximately $1.2,1.8$, and $2.4 \mu \mathrm{m}$ in response to the input currents of 20,30, and $40 \mathrm{~mA}$, respectively. 
Table 1. The experimental factors and their levels.

\begin{tabular}{cccc}
\hline Factor & Level 1 & Level 2 & Level 3 \\
\hline A. Tool Radius TR $(\mathrm{mm})$ & 0.3 & 0.5 & 1.0 \\
B. Cutting Speed CS $(\mathrm{m} / \mathrm{min})$ & 2 & 3 & 4 \\
C. Input Current IC $(\mathrm{mA})$ & 20 & 30 & 40 \\
D. Feed Rate FR $(\mu \mathrm{m} / \mathrm{rev})$ & 2.5 & 5 & 10 \\
E. Surface form & Concave & Convex & \\
\hline
\end{tabular}

\subsection{Data Analysis for the Taguchi Method}

The target optimisation can be categorised into nominal-the-best type, the-smallerthe-better type, the-larger-the-better type, etc. Generally, the signal-to-noise ratio $(\mathrm{S} / \mathrm{N})$ is used as the objective function for optimising the process parameters. It should be noted that the equation for $\mathrm{S} / \mathrm{N}$ could vary from one optimisation type to another. As the surface roughness of the spherical surface cutting process is a the-smaller-the-better type problem, $\mathrm{S} / \mathrm{N}$ is defined by Equation (7) [24] as follows:

$$
S / N=-10 \log _{10}\left[\frac{1}{n} \sum_{i=1}^{n} y_{i}^{2}\right]
$$

where $y_{i}$ is the value of the target characteristic under different noise conditions and $n$ is the number of noise conditions.

In this experiment, $y_{i}$ is the arithmetic roughness $S_{a}$ of different areas on the mould surface, which are characterised by the slope degree, and $n$ is the number of the measured slope degrees. To optimise the parameters for spherical surface cutting, levels that maximise $S / N$ should be selected for the factors that have a significant effect on surface roughness.

\section{Results and Discussions}

Table 2 summarises the measured arithmetic roughness $S_{a}$ at the four slope degrees on the machined spherical moulds, $S / N$, and $\overline{S_{a}}$ (the mean of $S_{a}$ ) for each $L_{18}$ orthogonal array experiment. By comparing these values, the effect of the levels for each factor on surface roughness can be identified and the optimal level for each factor can be determined.

Table 2. Surface roughness of the machined spherical moulds.

\begin{tabular}{|c|c|c|c|c|c|c|c|c|c|c|c|}
\hline $\begin{array}{l}\text { Test } \\
\text { No. }\end{array}$ & TR & CS & IC & FR & $\begin{array}{l}\text { Surface } \\
\text { Form }\end{array}$ & $\begin{array}{l}S_{a}(\mathrm{~nm}) \\
\mathrm{SD}=0^{\circ}\end{array}$ & $\begin{array}{l}S_{a}(\mathrm{~nm}) \\
\mathrm{SD}=5^{\circ}\end{array}$ & $\begin{array}{l}S_{a}(\mathrm{~nm}) \\
\mathrm{SD}=10^{\circ}\end{array}$ & $\begin{array}{l}S_{a}(\mathrm{~nm}) \\
\mathrm{SD}=15^{\circ}\end{array}$ & $\mathrm{S} / \mathrm{N}$ & $\begin{array}{l}\overline{S_{a}} \\
(\mathrm{~nm})\end{array}$ \\
\hline 1 & 0.3 & 2 & 20 & 2.5 & Convex & 5.3 & 5.3 & 10.9 & 5.4 & -17.1 & 6.7 \\
\hline 2 & 0.3 & 4 & 30 & 10 & Convex & 12.5 & 11.0 & 12.1 & 11.5 & -21.4 & 11.8 \\
\hline 3 & 0.3 & 3 & 40 & 5 & Convex & 12.4 & 5.4 & 5.5 & 5.5 & -17.9 & 7.2 \\
\hline 4 & 0.3 & 2 & 20 & 2.5 & Concave & 6.1 & 6.4 & 9.5 & 10.9 & -18.6 & 8.2 \\
\hline 5 & 0.3 & 4 & 30 & 10 & Concave & 13.3 & 11.6 & 12.9 & 12.5 & -22.0 & 12.6 \\
\hline 6 & 0.3 & 3 & 40 & 5 & Concave & 8.1 & 5.4 & 6.1 & 5.8 & -16.2 & 6.4 \\
\hline 7 & 0.5 & 4 & 40 & 2.5 & Concave & 7.3 & 5.9 & 7.3 & 7.7 & -17.0 & 7.0 \\
\hline 8 & 0.5 & 2 & 30 & 5 & Concave & 5.7 & 5.9 & 6.5 & 7.4 & -16.1 & 6.3 \\
\hline 9 & 0.5 & 3 & 20 & 10 & Concave & 8.0 & 8.4 & 9.7 & 10.5 & -19.3 & 9.1 \\
\hline 10 & 0.5 & 4 & 40 & 2.5 & Convex & 6.8 & 5.9 & 9.8 & 11.6 & -18.9 & 8.5 \\
\hline 11 & 0.5 & 2 & 30 & 5 & Convex & 6.9 & 6.0 & 9.3 & 10.7 & -18.5 & 8.2 \\
\hline 12 & 0.5 & 3 & 20 & 10 & Convex & 13.9 & 8.6 & 9.5 & 9.7 & -20.5 & 10.4 \\
\hline 13 & 1 & 2 & 40 & 10 & Convex & 6.5 & 6.1 & 6.9 & 7.1 & -16.5 & 6.7 \\
\hline 14 & 1 & 3 & 30 & 2.5 & Convex & 5.2 & 6.0 & 7.2 & 7.5 & -16.3 & 6.5 \\
\hline 15 & 1 & 4 & 20 & 5 & Convex & 5.6 & 6.0 & 7.9 & 7.5 & -16.7 & 6.8 \\
\hline 16 & 1 & 2 & 40 & 10 & Concave & 8.0 & 8.3 & 8.4 & 8.5 & -18.4 & 8.3 \\
\hline 17 & 1 & 3 & 30 & 2.5 & Concave & 5.8 & 7.2 & 9.8 & 12.2 & -19.2 & 8.8 \\
\hline 18 & 1 & 4 & 20 & 5 & Concave & 5.7 & 6.9 & 9.4 & 10.3 & -18.3 & 8.1 \\
\hline
\end{tabular}




\subsection{Surface Roughness Analysis}

\subsubsection{Average Arithmetic Roughness $\overline{S_{a}}$ for Various Levels of Each Factor}

Figure 7 shows the average arithmetic roughness $\overline{S_{a}}$ for various levels of each factor. For the level of $0.3 \mathrm{~mm}$ of the tool radius, its value is determined as the mean value of $\overline{S_{a}}$ with the same tool radius. (i.e., $\left.(6.7+11.8+7.2+8.2+12.6+6.4) \mathrm{nm} / 6=8.8 \mathrm{~nm}\right)$. It is found that the feed rate has a great effect on the arithmetic roughness, while surface form has the least, which could be negligible compared with other factors. Tool radius, cutting speed, and input current have almost the same difference in arithmetic roughness under the selected levels. In view of the effect of the level for each factor, cutting speed and feed rate display upward and down-then-upward trends, respectively. This finding is consistent with previous study [16]. A larger cutting speed causes less overlapping cutting cycles and thus a larger upfeed stroke in each vibration cycle, requiring a relatively higher material load to be removed. Moreover, a larger cutting speed leads to a higher ratio of the cutting speed to the maximal vibration speed, increasing the contact time between the tool and the workpiece, which reduces the lubrication performance and heat transfer during the cutting process. Both can induce a larger cutting force and hence poorer surface quality. Regarding the feed rate, it appears that a high feed rate results in a high material removal load and cutting force, causing instability and thus poor surface quality in the cutting process. By contrast, a too low feed rate may cause the uncut chip thickness to become comparative to the radius of the tool edge, which can induce significant ploughing and rubbing and thus lead to poor surface quality [16].

The tool radius exhibits a peculiar and interesting downward trend of arithmetic roughness with increasing level value. It is noted that the thrust force increases with increasing tool radius under the same cutting conditions. Nath et al. [25] found that a 0.6-mm tool radius achieved better surface quality than a smaller or a larger one when machining tungsten carbide using ultrasonic elliptical vibration cutting with a vibration frequency of $40 \mathrm{kHz}$. It was found that worse surface quality for a larger tool radius $(0.8 \mathrm{~mm})$ was caused by the increasing cutting force, leading to a break in the regenerative chatter suppression dynamics [26] and thus instability of the cutting process. This means that the tool radius can be improved without causing cutting instability to achieve smaller theoretical surface roughness if the vibration-assisted cutting technique can produce a smaller average force under the same cutting conditions. As shown in Figure 7, the optimal tool radius for minimum surface roughness in the applied $104 \mathrm{kHz}$ UVAC technique increases to equal to or maybe larger than $1 \mathrm{~mm}$. This appears to indicate that this technique may have a better cutting performance for surface finishes in the machining of steel. Moreover, the results show that all of the arithmetic roughness values under various levels of each factor are below $10 \mathrm{~nm}$, which could be regarded as another justification for the superiority of the surface quality in this high-frequency ultrasonic vibration-assisted cutting technique.

Input currents exhibit an up-then-downward trend of arithmetic roughness with increasing level value. It is understandable that the surface quality can be improved by increasing the input current of the vibrator, which generates increasing vibration amplitude. Increasing the vibration amplitude leads to an increase in the maximal vibration speed and thus a decrease in the speed ratio and cutting duty cycle. This results in better lubrication as well as heat transfer and hence better surface quality. However, it seems peculiar that the surface roughness with a current of $20 \mathrm{~mA}$ is lower than that for $30 \mathrm{~mA}$. One possible reason is that a smaller vibration amplitude makes the vibrator have better stiffness and stability so it undergoes less deflection when subjected to certain loading. 


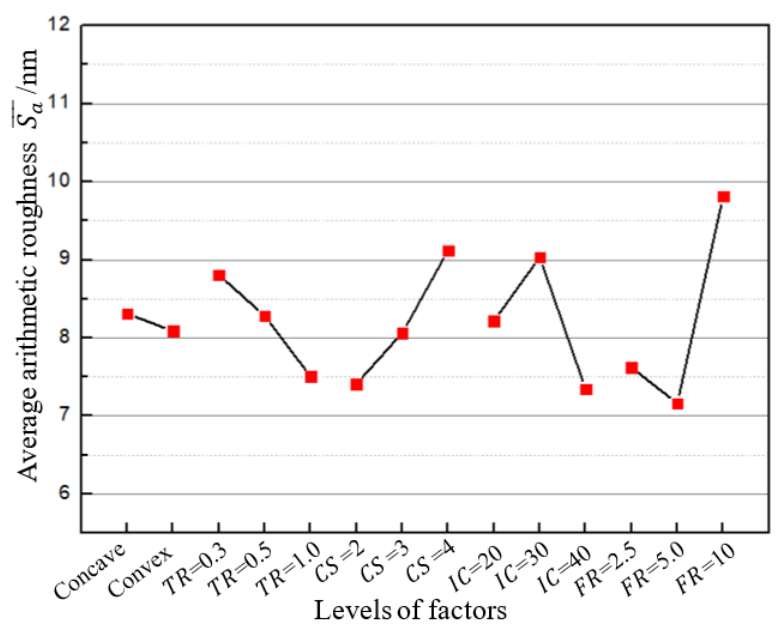

Figure 7. Average arithmetic roughness $\overline{S_{a}}$ of four slope degrees under various levels for each factor.

\subsubsection{Arithmetic Roughness $S_{a}$ for Each SD}

To study the effect of various slope degrees on the surface roughness, Figure 8 summarises the arithmetic roughness $S_{a}$ as a function of the slope degree of the workpiece. For the slope degrees $0^{\circ}, 5^{\circ}, 10^{\circ}$, and $15^{\circ}$, their values are determined as the mean value of $S_{a}$ in all of the orthogonal array experiments at the same slope degrees of $0^{\circ}, 5^{\circ}, 10^{\circ}$, and $15^{\circ}$, respectively. It was found that the surface roughness exhibits an upward trend with increasing slope degree, except at the slope degree of $0^{\circ}$. The arithmetic roughness at $0^{\circ}$ is higher than that for $5^{\circ}$. One possible reason for this is that the nominal cutting speed keeps changing with decreasing the cutting diameter in the central area of the workpiece because the rotational speed of the spindle remains constant after reaching $300 \mathrm{rpm}$ in this area. This constant change in cutting speed could result in instability of the cutting process, reducing the surface quality. Another reason is that the surface morphology in this area is more likely to be scratched and influenced by the flow chips. Excluding this special area, the arithmetic roughness of other slope degrees exhibited an upward trend. This machining phenomenon is not preferable to produce a homogeneous surface finish on the surface with geometry of great difference in the slope degree so the underlying reasons for this need to be analysed for the purpose of suppression.

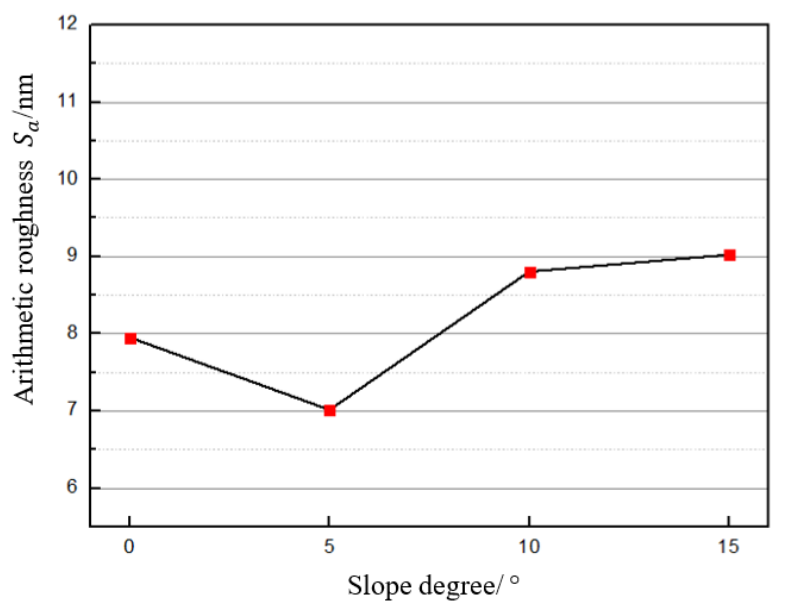

Figure 8. Arithmetic roughness $S_{a}$ with respect to various slope degrees.

An attempt was made to determine the possible reasons for this phenomenon. One could be due to the variation in tool force under various tool cutting angles due to varying slope degrees of the workpiece. With the increase in slope degree of the workpiece during the cutting process, the cutting point on the tool edge changes and thus the cutting angle be- 
tween the symmetric line of the tool rake face and the normal line of the tool edge at the cutting point increases as mentioned in Section 3.1. This leads to an increase in the lateral force loading on the cutting tool, which could probably cause cutting instability due to the relatively weak resistance to loading of the vibrator in the lateral direction, thus resulting in deterioration of the surface quality. To verify this speculation, tool force components during the cutting process at various cutting angles need to be measured and analysed.

To investigate the effect of cutting angle on the tool force during the cutting process, the tool force at the cutting angles of $0^{\circ}$ and $15^{\circ}$ was measured and compared. Figures 9 and 10 show a schematic and a photo of the experimental setup. The cutting tool with a nose radius of $1 \mathrm{~mm}$ and a rake angle of $0^{\circ}$ was used. In the case of the cutting angle of $0^{\circ}$, the tool was installed with the symmetric line of the tool rake face parallel to the Z-axis of the machine. In contrast, in the case of the cutting angle of $15^{\circ}$, the cutting tool together with the force sensor were clockwise rotated along the $Y$-axis by $15^{\circ}$ based on the condition of $0^{\circ}$ by the $\mathrm{B}$-axis of the machine (Top view). The desired nominal cutting speed, depth of cut, and feed rate of the practical cutting condition were $3 \mathrm{~m} / \mathrm{min}, 5 \mu \mathrm{m}$, and $10 \mu \mathrm{m} / \mathrm{rev}$, respectively. It is noted that it is impossible to acquire the actual transient tool force in the UVAC process as the vibration frequency is much larger than the natural frequency of the force sensor. As a result, the UVAC process was imitated by programming its tool trajectory as a conventional UVAC at a low frequency [27]. The imitated vibration frequency was set as $0.5 \mathrm{~Hz}$ with a peak-to-peak amplitude of $2 \mu \mathrm{m}$, and the actual nominal cutting speed was set as $14.4 \mu \mathrm{m} / \mathrm{min}$ to keep the upfeed stroke in each vibration cycle identical to that in the practical UVAC process.

In the experiment, face turning was conducted to flatten the workpiece. Following this, the cutting tool moved towards the workpiece at the given diameter by Z-axis until the desired depth of cut and started cutting for an rotation angle of $90^{\circ}$ to make the cutting process stable. After this, a programmed grooving test was conducted in the $C$-axis mode and the tool force was acquired by the Kistler force senser 9256C1. According to Arcona's force model [28], the tool force is proportional to the material hardness of the workpiece. To avoid excessive tool wear in low-frequency vibration cutting of steel while achieving a tool force identical to that in the machining of steel, electroless plated nickel with a hardness close to that of steel was selected as the cutting material. The measured tool force at the cutting angles of $0^{\circ}$ and $15^{\circ}$ in the grooving tests with 3 vibration cycles is presented in Figure 11a,b, respectively.

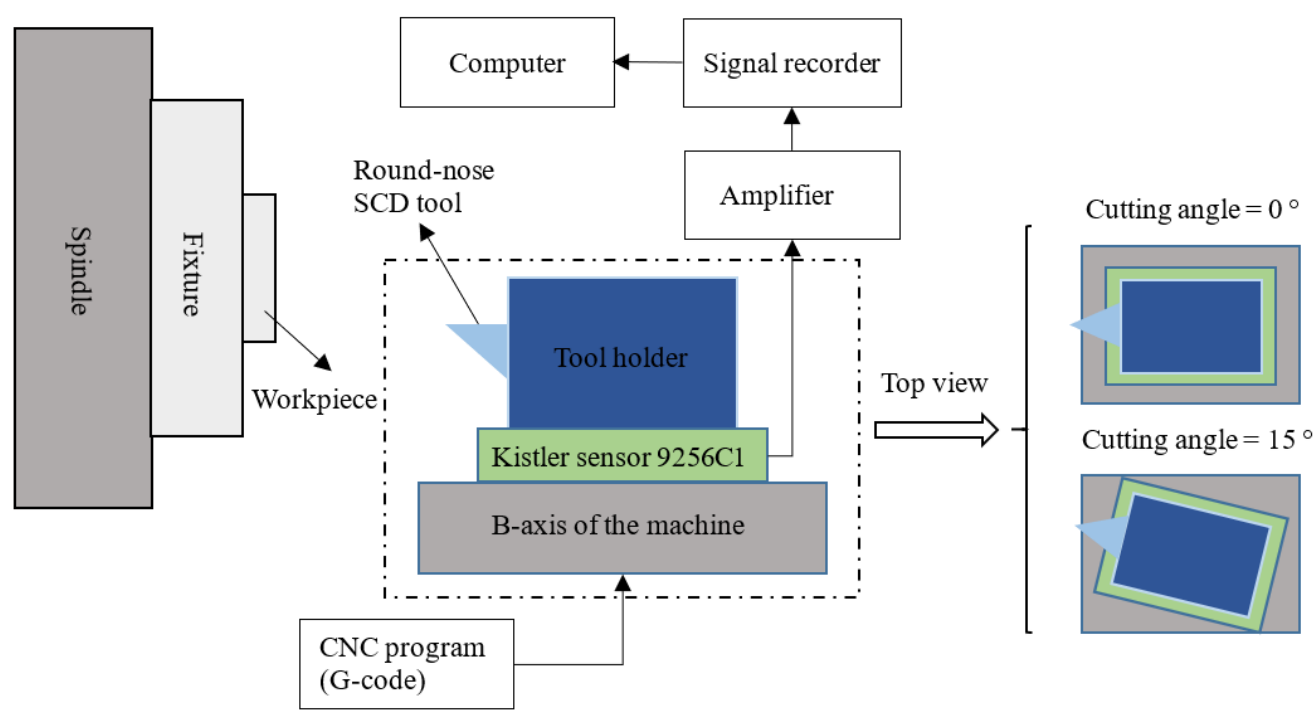

Figure 9. Schematic of the experimental setup for the low-frequency UVAC. 


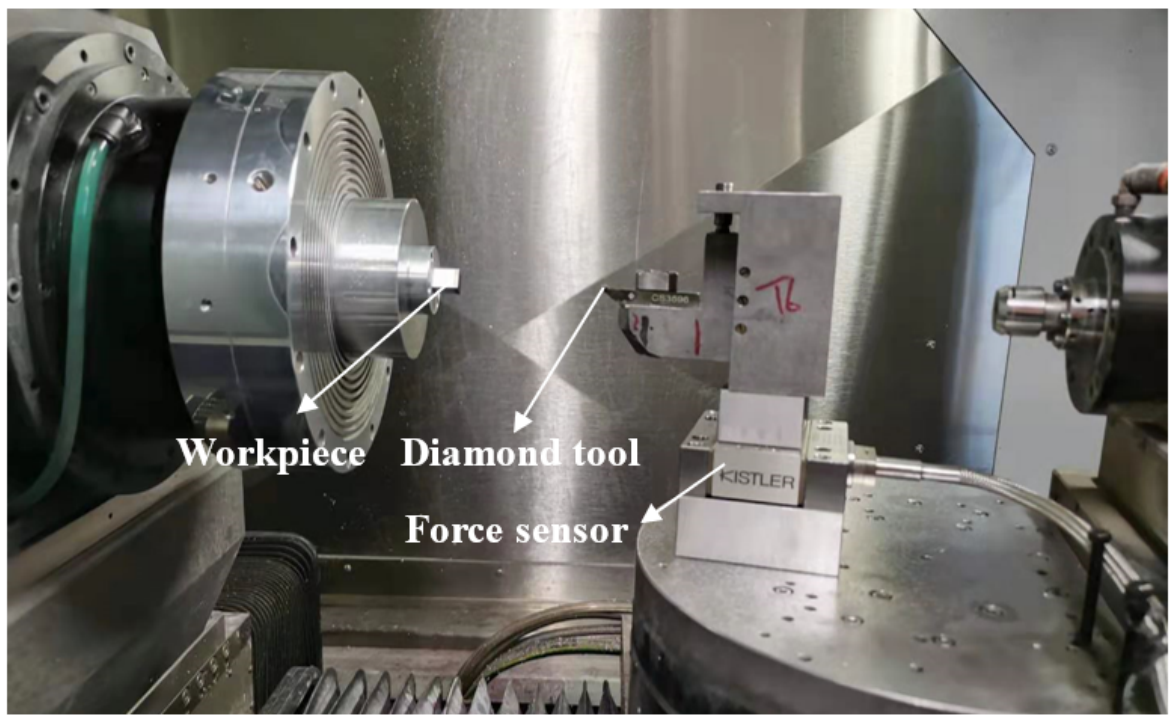

Figure 10. Photo of the machining setup for the low-frequency UVAC.
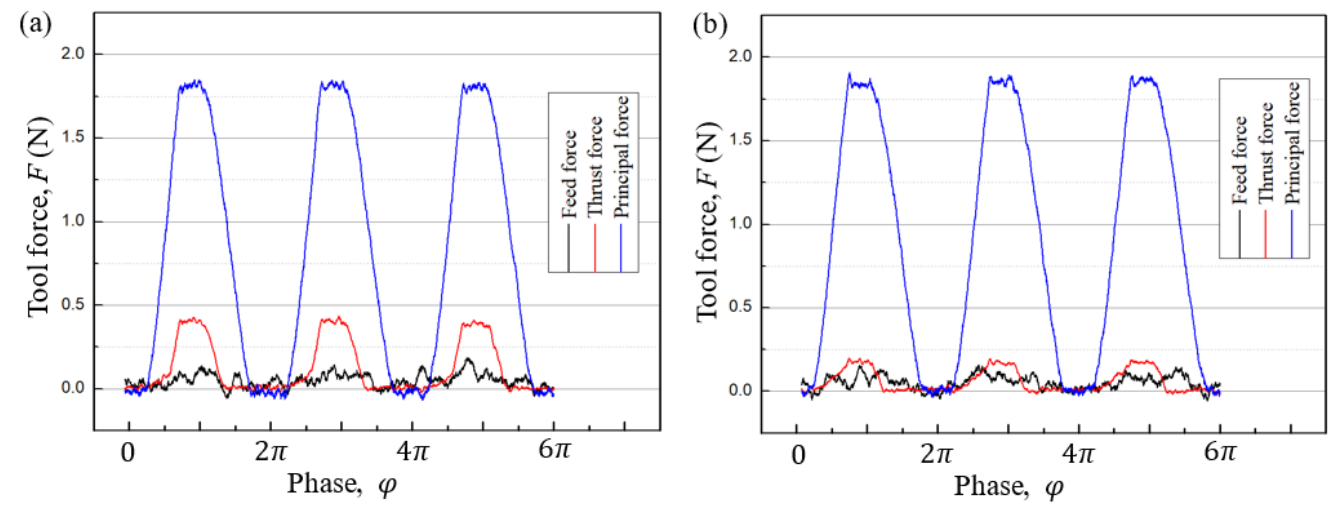

Figure 11. Tool force measured in the programmed grooving tests at various cutting angles: (a) $0^{\circ}$ and $(\mathbf{b}) 15^{\circ}, f=0.5 \mathrm{~Hz}, A=1 \mu \mathrm{m}, v_{\mathcal{C}}=14.4 \mu \mathrm{m} / \mathrm{min}$, depth of cut $=5 \mu \mathrm{m}$, and feed rate $=10 \mu \mathrm{m} / \mathrm{rev}$.

With an increase in the cutting angle from $0^{\circ}$ to $15^{\circ}$, the principal force remains constant, the thrust force decreases observably while the feed force increases slightly. Although this changing trend of tool force is consistent with our previous conjecturing, the thrust force and especially the feed force in the grooving test are within a small range $(<0.5 \mathrm{~N})$. The tool force in the turning machining process in which there is a smaller material removal rate is even smaller compared with the grooving test. As a result, the variation in tool force for the turning machining due to increasing cutting angle may have little influence on the cutting stability and therefore should not be regarded as the primary factor for declining surface quality at high cutting angles.

Another possible reason could be the variation in vibration amplitude along the tool edge. As the applied ultrasonic tooling system works in the multi-order bending mode, the sonotrode undergoes bending deflection during the vibrating process, as presented in Figure 12a. Consequently, the tool tip vibrates with the largest amplitude while the vibration amplitude decreases gradually from the centre of the tool edge to both of its sides, as shown in Figure 12b. The largest vibration amplitude at the central part of the tool edge allows for better machining conditions for lubrication and heat transfer to achieve a better surface finish. During UVAC of spherical steel moulds, the central part of the tool is used to machine the geometry with a small slope degree while the sideward part is used to machine the geometry with a large slope degree. As a result, the surface roughness of the machined spherical steel mould increases with increasing slope degree. 
(a)

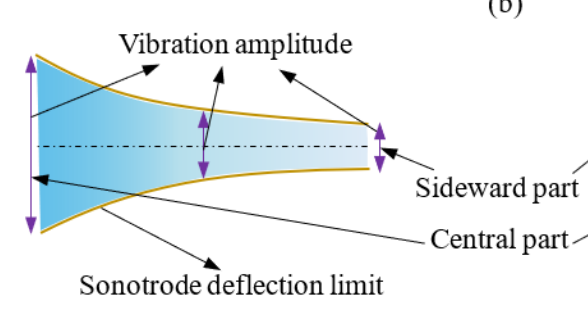

(b)

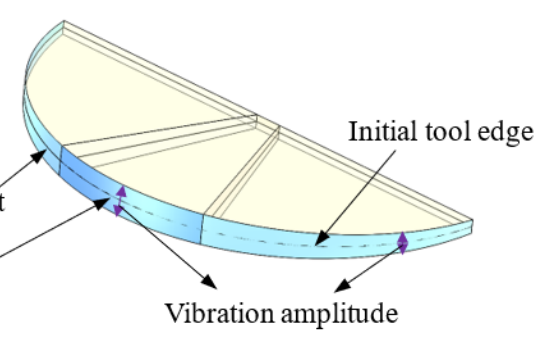

Figure 12. Schematic diagram of (a) the sonotrode deflection and (b) tool vibration amplitude distribution along the tool edge in the bending vibration mode.

\subsection{Optimisation of the Level for Each Factor}

To minimise the arithmetic roughness value of the machined spherical mould, the level for each factor that can maximise the $\mathrm{S} / \mathrm{N}$ ratio should be selected. Figure 13 plots the $\mathrm{S} / \mathrm{N}$ ratio of all levels for each factor. In practice, long-time use of UTS2 at the current of $40 \mathrm{~mA}$ possibly causes cutting instability, so the current of $20 \mathrm{~mA}$ is considered a better parameter value. As a result, the optimal combination of the level for each factor is determined to be $1 \mathrm{~mm}$ for tool radius, $2 \mathrm{~m} / \mathrm{min}$ for cutting speed, $20 \mathrm{~mA}$ for input current, and $5 \mu \mathrm{m}$ per rev for feed rate. Consequently, the convex mould was machined at the optimised parameters. Figure 14 shows the surface morphology and measured roughness of the machined convex mould at various slope degrees under optimised parameters. The arithmetic roughness $S_{a}$ of 3-4 nm could be achieved for all slope degrees. Furthermore, the arithmetic roughness $S_{a}$ is so small that the effect of the slope degree becomes insignificant. This means that the unevenness of the surface finish in machining the geometry with a great difference in slope degree using this ultrasonic tooling system can be alleviated by using an optimal combination of cutting parameters.

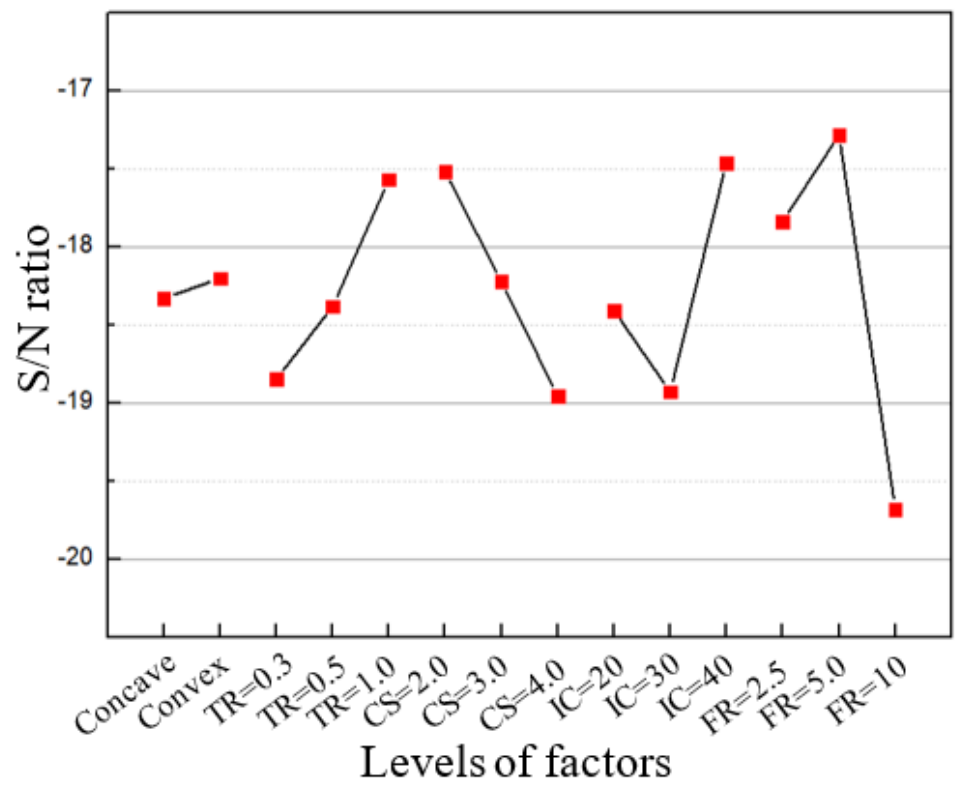

Figure 13. S/N ratio of levels for each factor. 

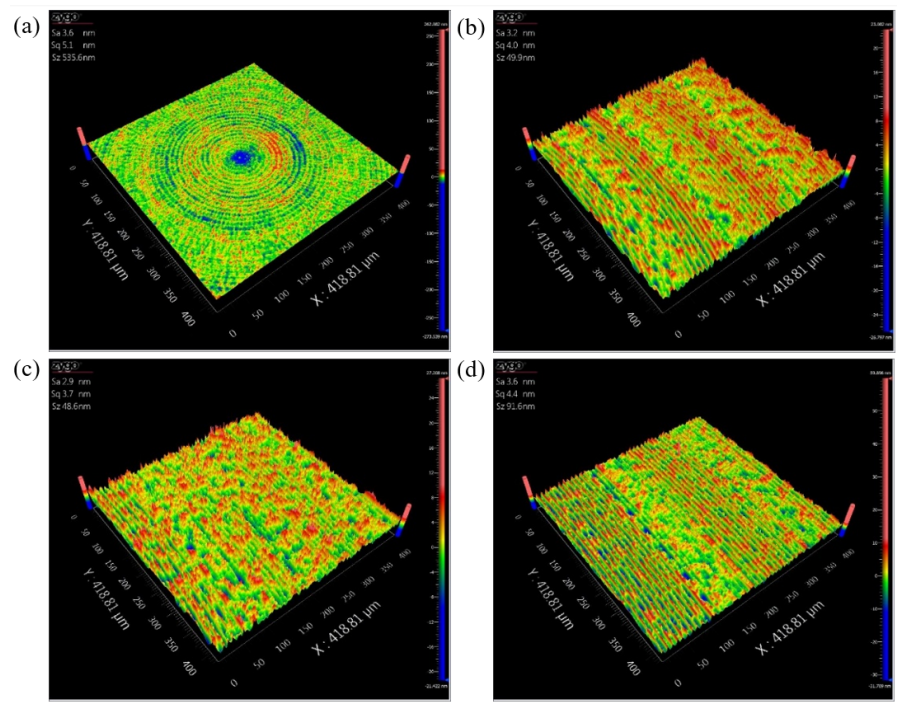

Figure 14. Surface morphology and measured roughness of the convex mould at different slope degrees under optimised parameters: (a) $0^{\circ}$, (b) $5^{\circ}$, (c) $10^{\circ}$, and (d) $15^{\circ}$.

\section{Conclusions}

This study investigated the effect of cutting parameters as well as the geometry of a workpiece on the surface roughness using high-frequency ultrasonic vibration-assisted cutting. The ultra-precision machined spherical moulds in this study were made of steel. Some findings are given as follows:

1. Feed rate has the greatest effect on the surface roughness of the workpiece: $5 \mathrm{um} / \mathrm{res}$ was able to achieve better surface roughness compared with $10 \mathrm{um} / \mathrm{res}$ and $2.5 \mathrm{um} /$ res. Under the selected levels of the other factors, surface roughness decreased with increasing tool radius while it increased with increasing nominal cutting speed. The effect of input current on surface roughness remains unclear based on the obtained results.

2. To achieve a better surface finish, the optimal combination of the level for each cutting parameter is $1 \mathrm{~mm}$ for tool radius, $2 \mathrm{~m} / \mathrm{min}$ for cutting speed, $20 \mathrm{~mA}$ for input current, and $5 \mu \mathrm{m}$ per rev for feed rate.

3. Arithmetic roughness on the machined spherical steel mould exhibited a slight upward trend with an increase in slope degree from $5^{\circ}$ to $15^{\circ}$, and the variation in vibration amplitude distribution along the tool edge arising in the bending vibration mode is speculated to be the possible reason.

4. Under optimal cutting conditions, the optical surface quality, with an arithmetic roughness $S_{a}$ of 3-4 nm, can be achieved at various slope Degrees. Furthermore, the unevenness of surface finishes at various slope degrees was alleviated in this ultrasonic tooling system with a combination of optimal parameters.

The results demonstrate the technical merits of using high-frequency ultrasonic vibration-assisted cutting in the machining of steel material with a superior surface finish. Further research will be conducted to continuously examine and verify the reason for the unevenness of surface quality in the machining of workpieces with complex geometries where there is a great difference in the slope degree to identify a strategy to improve the vibration setup.

Author Contributions: C.Z. (Chenyang Zhao), B.B., and C.C. conceived and designed the methodology and experiments; C.C. and B.B. contributed to the materials and machining tools; C.Z. (Canbin Zhang) and C.Z. (Chenyang Zhao) performed the experiments; C.Z. (Canbin Zhang) analysed the measurement data and wrote the draft on the technical content of the manuscript; C.C. reviewed and revised the detailed content of the manuscript. All authors have read and agreed to the published version of the manuscript. 
Funding: This research received no external funding.

Acknowledgments: The authors would like to express their sincere thanks for the financial support from the Research Office (project code: RK2Z) from The Hong Kong Polytechnic University. Special thanks are also due to the contract research project between the State Key Laboratory of Ultraprecision Machining Technology of The Hong Kong Polytechnic University and Son-X, Gmbh, Aachen, Germany.

Conflicts of Interest: The authors declare no conflicts of interest.

\section{Nomenclature}

The following abbreviations or physical quantities are used in this manuscript:

$\begin{array}{ll}\text { UVAC } & \text { Ultrasonic vibration-assisted cutting } \\ \text { SD } & \text { Slope degree } \\ S_{a} & \text { Arithmetic surface roughness } \\ \frac{S_{a}}{C B N} & \text { Average arithmetic surface roughness } \\ \text { SPDT } & \text { Cubic boron nitride } \\ \text { CUAC or 1D UVC } & \text { Conventional ultrasonic vibration cutting } \\ \text { UEVC } & \text { Ultrasonic elliptical vibration cutting } \\ \text { PCD } & \text { Poly-crystalline diamond } \\ f & \text { Vibration frequency } \\ A & \text { Vibration amplitude } \\ v_{C} & \text { Nominal cutting speed } \\ \text { DC } & \text { Duty cycle } \\ \text { TR } & \text { Tool radius } \\ \text { CS } & \text { Cutting speed, namely nominal cutting speed } \\ \text { IC } & \text { Input current } \\ \text { FR } & \text { Feed rate } \\ S / N & \text { Signal-to-noise ratio } \\ \text { CSS } & \text { Constant surface speed }\end{array}$

\section{References}

1. Vopát, T.; Sahul, M.; Haršáni, M.; Vortel, O.; Zlámal, T. The tool life and coating-substrate adhesion of AlCrSiN-coated carbide cutting tools prepared by LARC with respect to the edge preparation and surface finishing. Micromachines 2020, 11, 166. [CrossRef]

2. Kuntoğlu, M.; Aslan, A.; Pimenov, D.Y.; Giasin, K.; Mikolajczyk, T.; Sharma, S. Modeling of cutting parameters and tool geometry for multi-criteria optimization of surface roughness and vibration via response surface methodology in turning of AISI 5140 steel. Materials 2020, 13, 4242. [CrossRef]

3. Kumar, P.; Chauhan, S.R.; Pruncu, C.I.; Gupta, M.K.; Pimenov, D.Y.; Mia, M.; Gill, H.S. Influence of different grades of CBN inserts on cutting force and surface roughness of AISI H13 die tool steel during hard turning operation. Materials 2019, 12, 177. [CrossRef] [PubMed]

4. Ikawa, N.; Donaldson, R.R.; Komanduri, R.; König, W.; Aachen, T.H.; McKeown, P.A.; Moriwaki, T.; Stowers, I.F. Ultraprecision metal cutting-The Past, the Present and the Future. CIRP Ann. Manuf. Technol. 1991, 40, 587-594. [CrossRef]

5. Paul, E.; Evans, C.J.; Mangamelli, A.; McGlauflin, M.L.; Polvani, R.S. Chemical aspects of tool wear in single point diamond turning. Precis. Eng. 1996, 18, 4-19. [CrossRef]

6. Guo, J.; Zhang, J.; Pan, Y.; Kang, R.; Namba, Y.; Shore, P.; Yue, X.; Wang, B.; Guo, D. A critical review on the chemical wear and wear suppression of diamond tools in diamond cutting of ferrous metals. Int. J. Extrem. Manuf. 2020, 2, 12001.

7. Evans, C.; Bryan, J.B. Cryogenic diamond turning of stainless steel. CIRP Ann. Manuf. Technol. 1991, 40, 571-575. [CrossRef]

8. Casstevens, J. Diamond turning of steel in carbon-saturated Diamond turning of steel in carbon-saturated atmospheres. Precis. Eng. 1983, 5, 9-15. [CrossRef]

9. Moriwaki, T.; Shamoto, E. Ultraprecision diamond turning of stainless steel by applying ultrasonic vibration. CIRP Ann. Manuf. Technol. 1991, 40, 559-562. [CrossRef]

10. Coelho, R.T.; Ng, E.-G.; Elbestawi, M.A. Tool wear when turning hardened AISI 4340 with coated PCBN tools using finishing cutting conditions. Int. J. Mach. Tools Manuf. 2007, 47, 263-272. [CrossRef]

11. Aslan, E.; Camuşcu, N.; Birgören, B. Design optimization of cutting parameters when turning hardened AISI 4140 steel (63 HRC) with Al2O3+TiCN mixed ceramic tool. Mater. Des. 2007, 28, 1618-1622. [CrossRef]

12. Shamoto, E.; Moriwaki, T. Study on Elliptical Vibration Cutting. CIRP Ann-Manuf. Technol. 1994, 43, 35-38. [CrossRef] 
13. Shamoto, E.; Moriwaki, T. Ultaprecision diamond cutting of hardened steel by applying elliptical vibration cutting. CIRP Ann. Manuf. Technol. 1999, 48, 441-444. [CrossRef]

14. Li, L.; Yang, G.; Lee, W.B.; Ng, M.C.; Chan, K.L. Carbide-bonded graphene-based Joule heating for embossing fine microstructures on optical glass. Appl. Surf. Sci. 2020, 500, 144004. [CrossRef]

15. Mukaida, M.; Yan, J. Ductile machining of single-crystal silicon for microlens arrays by ultraprecision diamond turning using a slow tool servo. Int. J. Mach. Tools Manuf. 2017, 115, 2-14. [CrossRef]

16. Zhang, X.; Senthil Kumar, A.; Rahman, M.; Nath, C.; Liu, K. Experimental study on ultrasonic elliptical vibration cutting of hardened steel using PCD tools. J. Mater. Process. Technol. 2011, 211, 1701-1709. [CrossRef]

17. Klocke, F.; Dambon, O.; Bulla, B.; Heselhaus, M. Ultrasonic assisted turning of hardened steel with mono-crystalline ultrasonic assisted turning of hardened steel with mono-crystalline diamond. In Proceedings of the 10th International Euspen Conference, Zürich, Switzerland, 18-22 May 2008; pp. 165-169.

18. Klocke, F.; Dambon, O.; Bulla, B. Tooling system for diamond turning of hardened steel moulds with apsheric or non rotational symmetrical geometries. In Proceedings of the 11th EUSPEN International Conference, Como, Italy, $23-26$ May 2011.

19. Gaidys, R.; Dambon, O.; Ostasevicius, V.; Dicke, C.; Narijauskaite, B. Ultrasonic tooling system design and development for single point diamond turning (SPDT) of ferrous metals. Int. J. Adv. Manuf. Technol. 2017, 93, 2841-2854. [CrossRef]

20. Brehl, D.E.; Dow, T.A. Review of vibration-assisted machining. Precis. Eng. 2008, 32, 153-172. [CrossRef]

21. Moriwaki, T.; Shamoto, E.; Inoue, K. Ultraprecision ductile cutting of glass by applying ultrasonic vibration. CIRP Ann-Manuf. Technol. 1992, 41, 141-144. [CrossRef]

22. Zhang, X.; Deng, H.; Liu, K. Oxygen-shielded ultrasonic vibration cutting to suppress the chemical wear of diamond tools. CIRP Ann. Manuf. Technol. 2019, 68, 69-72. [CrossRef]

23. Zhang, X.; Liu, K.; Kumar, A.S.; Rahman, M. A study of the diamond tool wear suppression mechanism in vibration-assisted machining of steel. J. Mater. Process. Technol. 2014, 214, 496-506. [CrossRef]

24. Shiou, F.J.; Cheng, C.H. Ultra-precision surface finish of NAK80 mould tool steel using sequential ball burnishing and ball polishing processes. J. Mater. Process. Technol. 2008, 201, 554-559. [CrossRef]

25. Nath, C.; Rahman, M.; Neo, K.S. A study on the effect of tool nose radius in ultrasonic elliptical vibration cutting of tungsten carbide. J. Mater. Process. Technol. 2009, 209, 5830-5836. [CrossRef]

26. Xiao, M.; Karube, S.; Soutome, T.; Sato, K. Analysis of chatter suppression in vibration cutting. Int. J. Mach. Tools Manuf. 2002, 42, 1677-1685. [CrossRef]

27. Arefin, S.; Zhang, X.; Anantharajan, S.K.; Liu, K.; Neo, D.W.K. An Analytical Model for Determining the Shear Angle in 1D Vibration-Assisted Micro Machining. Nanomanuf. Metrol. 2019, 2, 199-214. [CrossRef]

28. Arcona, C.; Dow, T. A. An empirical tool force model for precision machining. J. Manuf. Sci. Eng. Trans. ASME 1998, $120,700-707$. [CrossRef] 